\title{
THE HISTORY OF THE RECTILINEAR DIAMETER LAW
}

\author{
Simón Reif-Acherman \\ Escuela de Ingeniería Química, Universidad del Valle, A. A. 25360 Unicentro, Cali, Colombia
}

Recebido em 5/1/10; aceito em 29/4/10; publicado na web em 1/9/10

\begin{abstract}
The formulation of the so-called law of rectilinear diameter for the determination of the critical volume of substances in the concluding decades of the nineteenth century became in a very useful and acceptably exact alternative tool for researchers in the field of critical phenomena. Its corresponding original expression, and even those of its early few modifications, were so mathematically simple that their use did not limit to exclusively contribute to remove the by then experimental obstacle for the estimating of this critical parameter, but also extended along several decades in the increasing applications of the principle of corresponding states.
\end{abstract}

Keywords; rectilinear diameter; critical density; history of science.

\section{INTRODUCTION}

The discovering of the critical phenomena by the French Baron Charles Cagniard de la Tour (1777-1859) in 1822, and its later development by the Scottish scientist Thomas Andrews (1813-1885) in the second half of the nineteenth century, became a decisive step in the efforts for studying the matter behaviour. ${ }^{1,2}$ The definitive establishment of the real role and meaning of the concept of critical point would come with the Johann Diderik van der Waals's (18371923) formulation of the principle of corresponding states several years later, which did not only allowed the definition of a new set of reduced variables, but also the initial possibility of needing only one universal equation of state as a basis for the estimation of different properties of several classes of compounds. ${ }^{3}$

A basic requirement for the use of this principle was the availability of the experimental values of the three critical constants, pressure, temperature and volume. The usual, and practically the only by then known, methods for the measurement of these critical parameters were essentially either Caignard de la Tour's, based on the vanishing of the meniscus on heating a liquid in a sealed tube, or Andrews's, based on the determination of isotherms at various temperatures and the selection of the one for which the horizontal part just disappeared. While the measurement of the critical temperature by using vapours of pure liquids boiling under known pressures was the easiest experimental procedure, and that of critical pressure only required the guarantee of absence of impurity in the compound of interest for a relatively simple procedure, the determination of the critical volume or density of a substance was a much more difficult matter. It was clear from that time that the reasons of this extreme difficulty were due to the natural peculiarities of the critical point, and, specifically, to the small curvature of the coexistence curve close to it, which leaded to great volume sensitivity with variations of temperature and pressure. The determination of the critical volume was generally subordinated to that of the critical temperature, and it was verified that experimental inaccuracies of the order of $0.1{ }^{\circ} \mathrm{C}$, for example, produced significant greater alterations in the volume. About one decade later the French physicist Luis Georges Gouy (1854-1926) raised the influence of the gravitational field on matter and its capacity for generating a sizeable density gradient in a supercritical fluid due to the large compressibility as a second reason for the inaccuracies in the determination of the critical volume. ${ }^{4}$

*e-mail: sireache@univalle.edu.co
The search for an alternative method for the determination of critical volume was increasingly turning into an evident need in the concluding part of the nineteenth century. Although the early investigators on the critical phenomena didn't establish this searching as an explicit objective, it would be incidentally reached in the course of the researches carried out in this field by two French scientists. The purpose of this article is to show the more relevant facts related with the formulation of the first analytical proposed method for the determination of the critical volume of pure compounds, from then known as the law of rectilinear diameter, as well as its first modifications. The fact that this method of determination is still nowadays cited with comparative purposes in the evaluation of newer and obviously more sophisticated analytical and experimental techniques for the estimation of this critical parameter emphasizes its importance. Some few modifications in the original nomenclature used by different scientists over the years this story succeeded were done in order to preserve the consistence of the full article.

\section{THE RESPONSIBLES OF THE ORIGINAL IDEA}

The Andrew's results about a symmetric description of what happened to liquid and vapour at the critical point aroused the interest of the scientific community on the subject. The initial interests of the researchers, focused on the determination of physical and thermodynamical properties in this region, were quickly involved in theoretical controversy over the interpretation of the experiments on the nature of the vapour-liquid transition. The polemic, which extended over several decades, set proponents of two basic conceptions against each other; one which defended the notion of continuity of states and the indistinctness of the two states in the supercritical condition, and the other which hold the theory of the differences between liquid and vapour molecules and the explanation of the critical phenomena in terms of the liquid dissolution in the vapour at the critical point. ${ }^{5}$ One incidental figure in this whole research program and the mentioned controversy was the French physicist Louis Paul Cailletet (18321913) (Figure 1). ${ }^{6}$

From the beginning the Cailletet's main interest was not focused on the formulation and discussion of sophisticated theories, but in the development and implementation of experimental techniques for studying the fluids's behaviour at high pressures. From the 1860's he centred the efforts of his lately scientific career especially in the study of the pressure influence, initially on the chemical phenomena and the spectral stripes, ${ }^{7,8}$ and later on the compressibility of gases and liquids, 


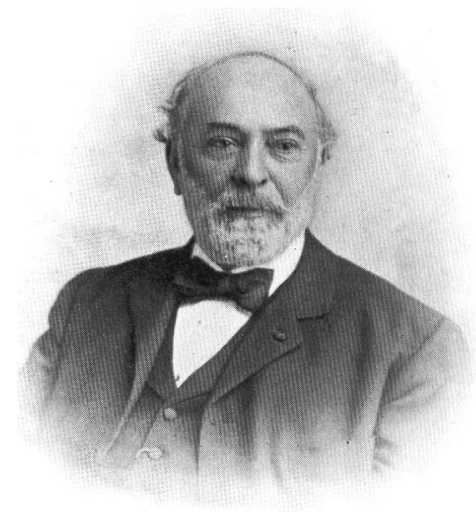

Figure 1. Louis Paul Cailletet (Courtesy of François Darbois)

studies in which he combined a great deal of technological skill and experimental curiosity. ${ }^{9}$ His most widely known achievement is the first liquefaction - almost simultaneously with Raoul-Pierre Pictet (1846-1929) - of oxygen in 1877, using a method that involved high compression, mild cooling and finally a sudden decrease in pressure. ${ }^{10}$ It was precisely through his researches on liquefaction of this and other gaseous compounds and their corresponding applications that Cailletet was involved in the studies on critical points. ${ }^{11,12}$ Although his description of the critical point phase transition was wrong, ${ }^{5}$ the skills he acquired by analyzing different details involved in the design not only of some apparatus but also of most of the instruments of measuring required for guarantee the precision in the whole research let clearly him for understanding the technical limitations of the lectures in the critical zone. ${ }^{13}$

Cailletet carried out great part of his whole research on liquefaction of gases at the École Normale Supérieure in the laboratory of the French chemist Henri Etienne Sainte-Claire Deville (1818-1881). It is there when he met the physicist of the Faculty of Sciences of Paris, Émile Ovide Joseph Mathias (1861-1942) (Figure 2), who became Préparateur in the Laboratory of Education of Physics at the Sorbonne. ${ }^{14}$ As Cailletet, Mathias didn't accept the notion of continuity of states, and, consequently, the identity of gaseous and liquid molecules. ${ }^{5}$ The Director at the Sorbonne was by then the also physicist Edmond Marie Leopold Bouty (1846-1922), who knew Cailletet in relation to the work they carried out together on the electric conductivity of metals. ${ }^{15} \mathrm{He}$ was the person that very probably recommended Mathias to the latter as assistant in his experiments.



Figure 2. Émile Ovide Joseph Mathias (Courtesy of the Président de Clermont Communauté and the Observatoire de Physique du Globe de ClermontFerrand)

\section{EXPERIMENTAL DETAILS OF THE RESEARCH WORK}

Cailletet and Mathias began in 1886 their research on the densities of liquefied gases and their saturated vapours. Their main interest was the possibility for studying the principle of corresponding states and its deviations. The definition of the more appropriate apparatus to be used for the determination of both saturated vapour and liquid densities, which showed then experimental difficulties at high pressures, become the first objective. The Figure 3 shows the apparatus designed by Cailletet and Mathias for determining liquid (left) and gas (right) densities. ${ }^{19}$
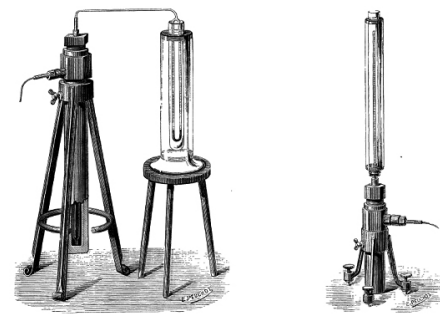

Figure 3. Apparatus for the determination of the (a) liquid and (b) vapour densities (from ref. 19)

The traditional procedure of the glass floats used by early experimentalists, such as, for example, Michael Faraday (1791-1867), for determining liquid densities as a part of his whole research on liquefaction of different gases, ${ }^{16}$ or other proposed by the Polish scientist Zygmunt Wroblewski (1845-1888) by comparing the gaseous and liquid volumes in equilibrium, ${ }^{17}$ led to only approximate results because of the compression effects and their limited ranges of application, and were consequently dismissed. The apparatus Cailletet and Mathias designed, based on a by then recent simple adaptation of the communicating vessels's principle, consisted of a reservoir of about $600 \mathrm{~cm}^{3}$ fixed to a big test tube in steel containing mercury. ${ }^{18}$ A glass tube O-shaped, composed of two equal finely graduated branches of about $0.5 \mathrm{~m}$ length and $1.5 \mathrm{~mm}$ internal diameter, also including a definite amount of mercury, was welded to the gas reservoir by other bent back twice tube. The compression of the gas in the reservoir by using a pump previously designed by Cailletet for his purpose, ${ }^{20}$ and the simultaneous refrigeration of one of the two branches of the graduated tube led to some evaporation of liquid and the condensation of other amount in the second branch. The liquid density could then be easily determined with the lectures of the mercury heights in both branches and the knowledge of the density of mercury. This design, which allowed to always working with the same weight of gaseous substance, was found to be resistant to pressures up to 200 atmospheres, correcting so the weakness of previous methods.

With regard to the vapour densities, the inapplicability of some original previous methods at higher pressures allowed again Cailletet and Mathias for designing different equipments to those previously used. ${ }^{21}$ The apparatus consisted of a precisely gauged thick tube welded to a cylindrical reservoir of about $60 \mathrm{~cm}^{3}$ opened in its low extreme. ${ }^{19}$ An exact determination of the total volume and the measurements of pressure and temperature allowed the estimation of the weight of the gaseous substance. The reservoir was screwed on to the test tube of the apparatus and this latter one jacketed with concentric tube containing a liquid at constant temperature. The saturation point was determined, following a procedure previously reported for the liquefaction of hydrochloric acid, ${ }^{22}$ by observing the cessation of the rising or decreasing of the lecture of a manometer with the gradual compression or decompression of the gas under consideration. The exact determination of the total volume, as well the pressure and temperature at saturation, allowed the estimation of the weight of the gaseous substance, and hence its density. 
Cailletet and Mathias reported experimental results for only three compounds in their first report. It was there where the authors did by first time reference, although minimal and without consider it as a law, to the possibility for determining the density in the critical point based on the graphical representation of the density of liquid $\rho l$ and of saturated vapour $\rho_{v}$ in equilibrium with it in the ordinates versus the temperature $t$ in the abscissas. After observing the linear behaviour of the locus of the points bisecting the joins of corresponding values of these orthobaric densities with temperature,

$$
\frac{1}{2}\left(\rho_{l}+\rho_{v}\right)=\rho_{0}+\alpha t
$$

where $\rho_{0}$ is the mean density and $\alpha$ a constant, different for each substance, they concluded that the intersection of this line with the critical temperature $t_{C}$ (where "the two curves would seem to be connected") would allow them to estimate the critical density (Figure 4). ${ }^{19}$ According to it, the equation took the form of

$$
\rho_{\mathrm{C}}=\rho_{0}+\alpha t_{\mathrm{C}}
$$

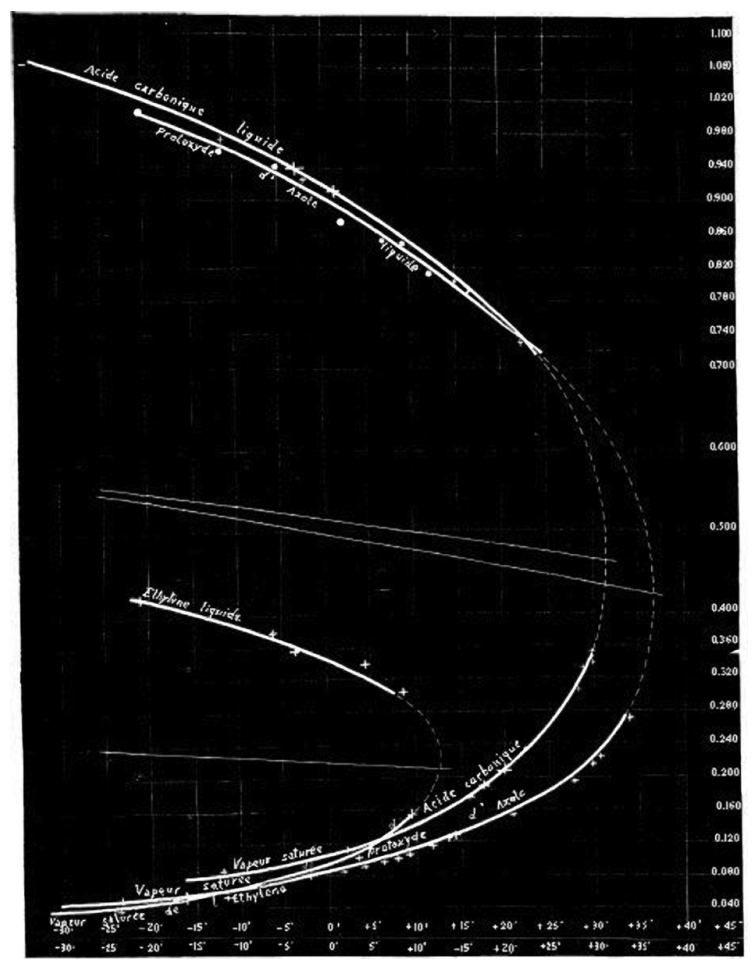

Figure 4. First graphical representation of the rectilinear diameter for nitrous oxide, ethylene, and carbon dioxide (from ref. 19)

The curves showed in Figure 4 indicate the values of critical density they found of $0.46,0.41$ and 0.22 for nitrous oxide, carbonic acid (carbon dioxide), and ethylene, respectively. While the two last values don't differ significantly of those nowadays accepted values of 0.214 and 0.468 ; that corresponding to nitrous oxide presents a relative error of about $10 \%$ regarding the actually used of $0.452 .{ }^{23}$ The successful results led Cailletet and Mathias to conclude that the same experimental techniques could be applied to all the substances whose critical temperature was higher than that corresponding to the freezing of mercury. ${ }^{19}$ Nevertheless, and in order to generalize the described method, they determined to also use it with substances with higher critical points, and chose sulphurous acid (sulphur dioxide) for that objective. These results were the subject of their second report. ${ }^{24}$ The corresponding critical density they found by using this original graphical method of 0.520 was very close to the nowadays accepted value of 0.525 . $^{23}$

The proposed law was confirmed about five years later by the French physicist Emile Hilaire Amagat (1841-1915) for the specific case of carbon dioxide, ${ }^{25}$ with new results of saturated liquid and vapour densities obtained by implementing different and remarkably more accurate techniques for its experimental determination. The new obtained critical density of 0.468 was far more closely to the actual value. ${ }^{26}$ The fact that the range of critical temperatures of the substances under study until the moment, with the only exception of sulphur dioxide, was very narrow, didn't allow still, however, a more complete confirmation.

\section{Improvements in the law}

Once the two mentioned reports were published, Cailletet seemed to have lost interest on the subject and focused his research work mainly on atmospheric phenomena and aeronautics. The only exceptions were some researches particularly focused in the study of water. ${ }^{27}$ Nevertheless, other person simultaneously appeared in the scene: the British chemist Sidney Young (1857-1937) (Figure 5). ${ }^{28}$ His interest on critical constants arose few years after his enrolment in 1882 as lecturer in Chemistry at University College, Bristol, as a consequence of a fruit partnership with his compatriot Sir William Ramsay (1852-1916), which lasted for 5 years.

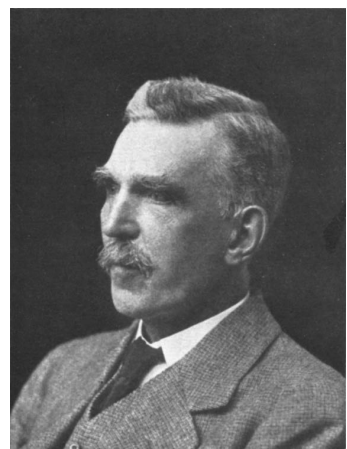

Figure 5. Sydney Young (Reprinted with permission from J. Timmermans, Endeavour 6, 11-14. Copyright 1947)

When Young came to Bristol, he found Ramsay engaged in two main investigations: the determinations of specific volumes of liquids at their boiling points, and of vapour pressures and critical constants of benzene and ether. Ramsay convinced Young to get involved in the searching of possible relationships among the behaviour of different compounds at equal values of reduced variables, according to deductions made by Johan Diderik van der Waals at setting out his equation of state. ${ }^{29}$ The verification process required the disposal of great amount of experimental data, such as liquid and vapour densities, vapour pressures, and, of course, critical constants of the compounds under consideration. Young was conscious of the technical difficulties for directly determining the critical density and after to suggest different experimental procedures and some analytical relations he finally decided to proceed with the method of Cailletet and Mathias and verify its accuracy. Using a new method for the determination of saturated densities in both states, ${ }^{30}$ he was able to state the validity of the law, although with some few quantitative differences. ${ }^{31}$ The compounds included in the study were benzene and three of its halogen derivates, carbon tetrachloride, stannic chloride, acid acetic, ether and three alcohols, with temperatures that went up until $325^{\circ} \mathrm{C}$. Very quickly the verification process included five of the lower esters (methyl formate, methyl acetate, methyl propionate, ethyl formate and ethyl acetate). The constants $\left(\mathrm{A}=\rho_{0}\right)$ are given in Table $1 .{ }^{32}$ 
Table 1. Young's constants for the right line of the rectilinear diameter for five lower esters

\begin{tabular}{llc}
\hline Substance & A. & $\alpha$. \\
\hline Methyl Formate $\ldots \ldots \ldots$ & .5025 & -.0007155 \\
Methyl Acetate $\ldots \ldots \ldots$ & .4839 & -.0006740 \\
Ethyl Formate $\ldots \ldots \ldots$ & .4759 & -.0006490 \\
Ethyl Acetate $\ldots \ldots \ldots$. & .4644 & -.0006250 \\
Methyl Propionate $\ldots \ldots$ & .4721 & -.0006210 \\
\hline
\end{tabular}

The verification of the law showed not be, however, perfect. The three alcohols, methanol, ethanol and propanol, and specially the first one, showed a very decided curvature, too pronounced to be neglected. Although Mathias initially considered these results within the range of probable experimental errors, this first notice of exceptions to the supposed universality of the proposed law rose his' and Young's interests for deeper analysis.

In order to preserve the utilization of a so simple and useful law, Young decided to undertake a careful experimental research that involved 30 compounds. One objective was to try of correlating the circumstances of the abnormal results and to classify the observed deviations according to some new clearly defined theoretical parameters, which must to be characteristic for each substance. Although separately exposed, the Mathias's and Young's approaches coincided in their selection. The first parameter for studying was the ratio of the actual to the theoretical (for an ideal gas) density, $\rho_{C} / \rho_{C}$, both evaluated at the critical point. Mathias, and something later Young and the Swiss chemist Philippe A. Guye (1862-1922) had separately concluded that a requisite for the true observance of the van der Waals's equation (and others equations of state by then known too, as that by Clausius for example) for normal substances (it meant those whose molecules underwent no dissociation or polymerization) was that this ratio should to be strictly constant. ${ }^{31,33,34}$ The value of this parameter could to serve as a criterion for evaluating the degree of complexity of molecules, which in their opinion should to be related with the observed departures of the estimated values of the critical density for alcohols. According to van der Waals, the value of this constant was $8 / 3$, or 2.6 , which derived from the author's observation about that the volume correction depending on the molecular size in the equation, $b$, was equal to 4 times the real volume occupied by spherical molecules under normal conditions of pressure and temperature. Young fulfilled the requisite at replacing the coefficient 4 by $4 \sqrt{ } 2$, previously suggested by the German physicist Oskar Emil Meyer (1834-1909), ${ }^{35}$ which led him to a constant ratio of 3.77 for all the substances included in the study.

A second parameter was related with the slope of the rectilinear diameter for each substance. Mathias similarly showed that in order to guaranty the obedience of these lines to the corresponding states principle the angular coefficient $\alpha$ should to be directly proportional to the critical densities of the respective substances and inversely proportional to their absolute critical temperatures. ${ }^{33}$ In mathematical terms, for each substance,

$$
\alpha=\text { constant } \frac{\rho_{\mathrm{C}}}{T_{\mathrm{C}}} \text { or } \alpha \frac{T_{\mathrm{C}}}{\rho_{\mathrm{C}}}=\text { constant }=a
$$

The whole experimental program had, however, significant limitations. In the great majority of cases the only densities experimentally determined were those of the liquids at temperatures below the boiling point. If the vapour pressures were known, the saturated vapour densities at these low temperatures were then calculated by using the van der Waals's equation of state, and thus the mean densities of both values could to be ascertained. The data of critical temperature became the main obstacle. If it was known, the critical density was then calculated by following the law of Cailletet and Mathias. But as for most substances the critical temperature had not been by then directly determined, Young must to use an alternative analytical formula for its estimation. The selected empirical expression was one deduced by Thorpe and Rücker, ${ }^{36}$ which combined the van der Waals's theory with an expression developed by the Russian chemist Dmitri Ivanovich Mendeleev (1834-1907), ${ }^{37}$

$$
T_{\mathrm{C}}=\frac{T_{2} \rho_{l 1}-T_{1} \rho_{l 2}}{B\left(\rho_{l 1}-\rho_{l 2}\right)}
$$

where $\rho_{l 1}$ and $\rho_{l 2}$ were the densities of the substance in liquid state at temperatures $T_{1}$ and $T_{2}$, respectively, and $B$ an universal constant. Although the authors had recommended a value for $B$ of 1.995, Mathias had showed that if it was equal to 2, then it followed that $\alpha=1$ and it would be then possible to ascertain both the critical density and temperature by using geometrical methods. It was later demonstrated that not only the suggested value for $B$ led to low accuracy, but that it always differed sensibly from 2 as well as $\alpha$ from the unity, with which the geometrical method became inapplicable.

In a detailed paper published some years later, Young reached important conclusions. ${ }^{38}$ The first one arose as an unplanned consequence of the incidental range of temperatures in which he worked. According to the by then existing experimental limitations, he found himself forced to use densities data at different intervals of temperature for determining the values of the mean densities for each one of the 30 substances. While for some of them he used experimental information between the respective normal boiling points and some few degrees below to their critical points, for the others the densities used for his conformation of the law corresponded to temperatures between $0{ }^{\circ} \mathrm{C}$ and the mentioned boiling points. After the analysis of the full package of results he was able to conclude that while the errors involved in the use of the simple right line proposed by Cailletet and Mathias rarely exceeded $0.25 \%$, and generally not exceeded $0.1 \%$ for the first interval of temperatures, they were considerably higher for the other range. As it could be easily imagined, Young found significant differences between the pair of constants calculated by using experimental data from one or other range This observation allowed him to suggest a more reliable representation of the locus of the mean value of densities by using a equation, which after intersecting the critical temperature took the form:

$$
\rho_{\mathrm{C}}=\rho_{0}+\alpha t_{\mathrm{C}}+\beta t_{\mathrm{C}}^{2}
$$

where the constants $\rho_{0}, \alpha$, and $\beta$ must to be calculated again for each substance. For the alcohols, however, he proposed to add a fourth term, $\gamma t_{\mathrm{C}}{ }^{3}$, in order to get a satisfactory agreement. The constants for the thirty substances are shown in Table 2 . The circumstance by which all the values of $\alpha$ are negative in both formulas, the simplest one and the extended, is consequence of the fact that the variation of the saturated liquid density is always greater than that of saturated vapour. The values of the constant $\beta$ found by Young were positive for some substances and negative for others.

The marked rapid increasing in the deviations Young observed with regard to the using of the law of Cailletet and Mathias below the boiling point was reinforced with the different types of curvature showed by plotting the differences against temperature for several substances. The examples shown in the Figure 6 cover different possibilities $\left(D_{C} / D_{C}=\rho_{C} / \rho_{C}\right)$. Pentane, the only substance of those under investigation that didn't show the slightest deviation from the law of Cailletet and Mathias and for which $\beta$ is obviously equal to 0 , could be presented as a reference point. Young also concluded that 
Table 2. Young's constants for the extended formula of the rectilinear diameter for thirty substances

\begin{tabular}{|c|c|c|c|c|}
\hline Name & $\mathrm{D}_{0}$ & $\alpha \times 10^{7}$ & $\beta \times 10^{10}$ & $\gamma \times 10^{13}$ \\
\hline Carbon Tetrachloride & .8165 & -9564 & +1480 & \\
\hline Hexamethylene & .3985 & -4685 & +791 & \\
\hline Isopentane & .3202 & -4658 & +463 & \\
\hline Stannic Chloride & 1.1387 & -12760 & +977 & \\
\hline Benzene & .4501 & -5248 & +693 & \\
\hline Di-isopropyl & .3401 & -4445 & +413 & \\
\hline Normal Pentane & .3232 & -4610 & 0 & \\
\hline Fluorbenzene & .5236 & -6000 & +293 & \\
\hline Chlorobenzene & .5640 & -5337 & -509 & \\
\hline Iodobenzene & .9303 & -7556 & -519 & \\
\hline Di-isobutyl & .3550 & -4115 & -592 & \\
\hline Ether & .3685 & -5377 & -475 & \\
\hline Bromobenzene & .7609 & -6655 & -725 & \\
\hline Normal Hexane & .3388 & -4445 & 0 & \\
\hline Normal Heptane & .3504 & -4192 & -621 & \\
\hline Methyl Isobutyrate & .4558 & -5593 & -689 & \\
\hline Normal Octane & .3590 & -3954 & -1046 & \\
\hline Propyl Formate & .4647 & -5748 & -459 & \\
\hline Ethyl Formate & .4741 & -6251 & -694 & \\
\hline Methyl Propionate & .4696 & -5921 & -729 & \\
\hline Methyl Butyrate & .4601 & -5430 & -906 & \\
\hline Ethyl Propionate & .4564 & -5644 & -784 & \\
\hline Methyl Formate & .5020 & -7013 & -665 & \\
\hline Propyl Acetate & .4553 & -5469 & -1124 & \\
\hline Methyl Acetate & .4799 & -6280 & -1467 & \\
\hline Ethyl Acetate & .4624 & -5992 & -764 & \\
\hline Ethyl Alcohol & .4028 & -3827 & -5940 & +651 \\
\hline Propyl Alcohol & .4095 & -3790 & -3750 & -5533 \\
\hline Methyl Alcohol & .4050 & -4479 & +1330 & -23760 \\
\hline Acetic Acid & .5355 & -5366 & -1191 & \\
\hline
\end{tabular}

the deviations from the simplest form of the law, or the curvatures in geometrical terms, were generally smaller the nearer $\rho_{C} / \rho_{C}$ approached the normal value of 3.77 and the nearer $a$ approached the value of 0.93 . In nearly every case, the showed curvature was in opposite directions according to $\rho_{\mathrm{C}} / \rho_{\mathrm{C}}$ was greater or less than 3.77 , and $a$ was greater or less than 0.93 . It was found too that $\beta$ was positive whe0 $\rho_{C} / \rho_{C}$ was lower than 3.77 and negative when it was higher.

\section{Among confirmations, limitations, extensions and alternative expressions}

The conclusions reached by Young put the law in its true place. The so called law was not universal and the existing deviations were mainly associated with the nature of substances and the range of temperatures in which the required saturated densities data for its application were estimated. As with Cailletet, the Young's interests began to slightly move to other fronts, such as the experimental determination of vapour pressures and boiling points of specific groups of substances and probable correlations between them, and didn't work more on the rectilinear diameter. Mathias unsuccessfully

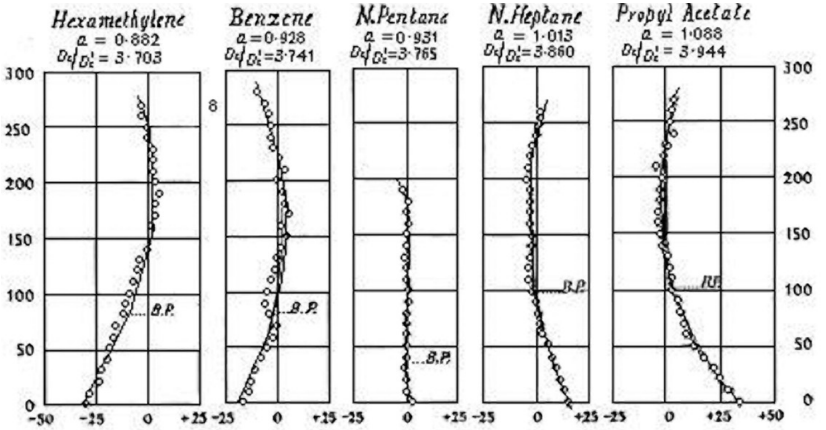

Figure 6. Observed deviations of the estimations by using the law of Cailletet and Mathias below the boiling point of the substances (from ref. 38)

tried to generalize the estimation of $a$ by correlating it with different variables in the framework of the principle of corresponding states. ${ }^{39}$ The experimental evidence on the variability of this parameter led him to also conclude about the non-universality of the principle. This fact could to be historically interpreted as one of the first suggestions about the requirement for including in the principle new parameters related with the nature of substances in addition to the reduced variables proposed by van der Waals.

Mathias continued insisting in the verification of the law. After verifying the law with acetylene, ${ }^{40}$ his experimental work was translated abroad. The full program of liquefaction of the so-called permanent gases carried out by the Dutch physicist Heike Kamerlingh Onnes (1853-1926) at his laboratory at the University of Leiden from the last quarter of the XIX century became an excellent opportunity for his purposes. The expectation that the diameter of the densities curve would reveal a characteristic feature of the whole representation of the different behaviours and their respective analytical reduced equations of state for substances with very low critical temperatures with regard to those of the compounds by then considered as normal, put this parameter in the first front of whatever comparative study. ${ }^{41}$ Mathias received financial support from the French Academy of Sciences for his journey and stay at The Netherlands in at least two opportunities, 2000 francs in $1909,{ }^{42}$ and 4000 francs in $1920 .{ }^{43}$ The money came from some funds created in 1908 by the Prince Roland Napoleon Bonaparte (1858-1924) for the promotion of the scientific research. ${ }^{44}$ During the periods Mathias was summer guest at Leyden, initially between 1910 and 1923 with Kamerlingh Onnes as host, and until 1932 with the also Dutch physicist Claude August Crommelin (1878-1965) as the new director of the laboratory, he collaborated with the measurement of the coexistence curves and the estimation of the parameters of the mathematical expression of the rectilinear diameter of many fluids such as oxygen, ${ }^{45}$ argon, ${ }^{46}$ nitrogen, ${ }^{47}$ hydrogen, ${ }^{48}$ neon, ${ }^{49}$ helium, ${ }^{50}$ ethylene, ${ }^{51}$ carbon monoxide, ${ }^{52}$ and krypton. ${ }^{53}$ The Figure 1S, supplementary material, shows the schematic arrangement used in these researches for the specific case of oxygen.

As the experimental procedures for the measurement of densities slowly became more precise, ${ }^{54}$ different reviews of critical constants for several substances began to be published..$^{54,55}$ The comparison of the reported values with those calculated by assuming the rectilinear behaviour of the diameter increased the possibilities for finding examples of deviations to the proposed law. Unlike most papers published by the Leyden Physical Laboratory, these deviations were well above the limits of experimental errors usually estimated between 0.5 and $2.0 \%$, and, occasionally higher. These deviations, which were a clear consequence of the discontinuous character of the densities curves, were specifically apparent in the vicinity of the critical point and were related with the yet mentioned extreme experimental difficulties for working in this zone. The Figure 7 shows the results found in the beginnings of the XX century for 
the specific case of sulfur dioxide, where accurate measurements of the critical density indicated a difference of $1.36 \%$ between the experimental value and that calculated with the relationship of Cailletet and Mathias. ${ }^{56}$

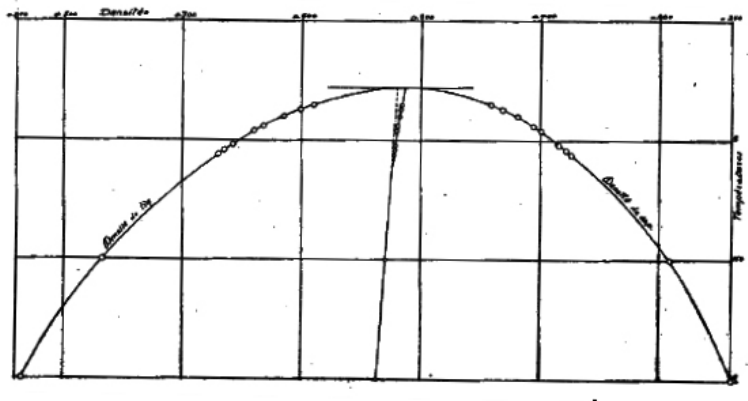

Figure 7. Representative graph of the deviations to the law of rectilinear diameter for sulfur dioxide (from ref. 56)

The evidence of deviations to the law raised as well the interest of researchers for proposing alternative analytical expressions for a more precise estimation of the critical density. The Dutch chemist Johannis Jacobus van Laar (1860-1938) and the German professor of physical chemistry Walther Hertz (1855-1930) modified the law by stating the following expression for density as a function of temperature,

$$
\rho=\rho_{0}(1-\alpha T)
$$

where $\rho_{0}$ is the density at absolute zero and $\alpha=\left[\delta /(1+\delta) T_{\mathrm{C}}\right] \cdot{ }^{57}$ For normal substances $\delta=0.9$, hence $\alpha=1 / 2.1 T_{\mathrm{c}}$ and $\rho=\rho_{0}\left(1-T / 2.1 T_{\mathrm{C}}\right)$, from which the density at $0 \mathrm{~K}$ may be calculated, with only a pair of experimental values. The critical density was then easily estimated by evaluating the Equation 6 for $T_{\mathrm{C}}$.

Two other expressions that proclaimed to supply more satisfactory results than those gotten by using the law by Cailletet and Mathias didn't receive, however, any additional repercussion. The first one, arisen as a consequence of the initial development of an equation for the calculation of the heat of vaporization of normal and nonassociated substances. ${ }^{58}$ It stated,

$$
\rho_{\mathrm{C}}=\frac{\rho_{l}+\rho_{v}}{2}+\frac{\rho_{0}}{2 T_{\mathrm{C}}^{0.3}}\left(T_{\mathrm{C}}-T\right)^{0.3}-\frac{\left(\rho_{0}-\rho_{\mathrm{C}}\right)}{T_{\mathrm{C}}^{0.4}}\left(T_{\mathrm{C}}-T\right)^{0.4}
$$

where $\rho_{l}$ and $\rho_{v}$ are the saturated liquid and vapour densities, respectively, at the temperature $T$. The other one had a similar mathematical simplicity than that of the rectilinear diameter but was verified only for very few compounds. ${ }^{59}$ It was

$$
\rho_{C}^{2 \beta}=\frac{\rho_{l}^{2 / 3}+\rho_{\mathrm{v}}^{2 / 3}}{2}
$$

Mathias himself, and the Austrian professor Hanns von Jüptner, proposed the different expression,

$$
\rho_{\mathrm{C}}=\frac{\frac{1}{2}\left(\rho_{l}+\rho_{v}\right)}{1+a\left(1-T_{\mathrm{r}}\right)}
$$

where $T_{\mathrm{r}}$ is the reduced temperature and $a$ a characteristic function of the critical temperature. ${ }^{41,60}$ According to Mathias, $a=b T_{\mathrm{C}}{ }^{n}$, where $b$ is a specific constant for each particular substance and $n$ an universal constant very close to 0.25 .

Other work suggest the possibility for estimating the angular coefficient $\alpha$ from characteristic parameters of each substance,

$$
\alpha=\frac{0.254 \rho_{\mathrm{b}}}{T_{\mathrm{C}}-T_{\mathrm{b}}} \text { or } \alpha=\alpha_{\mathrm{b}} \rho_{\mathrm{b}}-\frac{0.122 M}{T_{\mathrm{b}}^{2}}
$$

where $\rho_{b}$ and $\alpha_{b}$ are the liquid density and the coefficient of expansion of the liquid at the boiling point $T_{\mathrm{b}}{ }^{61}$

A renewed interest in the subject of rectilinear diameter arose from 1970's. The initial very little or no one experimental support for the theoretically predicted deviation from a linear diameter on the liquid-vapour transition near the critical point strongly changed. ${ }^{62,63}$ The report of the coexistence curves of some metals (rubidium and cesium) offers evidence of significant singularity in the diameter of the predicted form. ${ }^{64}$ Several suggestions have been proposed based on the analysis of these results, which include, as an example, a linear dependence of the slope of the diameter with the acentric factor of the substance and the possibility for relating it with the shape of the pair potential. ${ }^{65} \mathrm{~A}$ more recent approach, based on the philosophical structure of the law of rectilinear diameter, allows the estimation of the critical density without the help of the critical temperature. ${ }^{66}$ The mathematical relationship, so-called "the model of three densities", derived from two empirical equations for the surface tension and with a general pattern suggested by the graphic image of the coexistence system with the rectilinear diameter of Cailletet and Mathias, states that

$$
\frac{\rho_{l}}{\rho_{C}}-1 \frac{\rho_{v}}{\rho_{C}}=A\left[-\left(\frac{\rho_{C}}{\rho_{l}}\right)^{2 / 3}\right]^{3 / 2}
$$

where $A$ is a universal constant. If the only single data point of coexisting densities required for the method is taken at a pressure of one atmosphere, for example, the relationship may be written as

$$
\rho_{C}=0.348579 \rho_{l n b p}+6.34333 \rho_{v n b p}
$$

where $\rho_{l n b p}$ and $\rho_{v n b p}$ are the coexisting densities. The values of the two constants were determined on the statistical analysis of a data base of 183 substances used in the research, which included elements and inorganic and organic compounds. According to the author of this research, the testing of the performance of this equation with the data base gave a mean absolute difference of $1.24 \%$ and maximum difference of $5.77 \%$.

Although the rectilinear diameter rule has recently satisfactorily verified for some specific substances, ${ }^{67}$ it is generally nowadays considered incorrect for the full group of elements and compounds, and non-analytic contributions determine the behaviour when approaching the critical point. ${ }^{68}$ The relative importance of the various non-analytic terms determining the asymptotic behaviour is difficult to assess and remains an actual topic of experimental and theoretical investigations. ${ }^{69}$

\section{CONCLUDING REMARKS}

The so-called law of Cailletet and Mathias becomes an interesting case in the study of the volumetric and thermodynamic properties of substances because of the continued actuality it had evidenced from the initial formulation. Its original empirical character has not any doubt in a historical context. Two elements support this assertion: the fact that there is not any minimal suggestion in the available historical accounts that allow us to affirm that Cailletet and Mathias knew intuitively the existence of a mathematical relation between the densities of the liquefied gases and their saturated vapours in 1886, and the publication, initially in a very specific lattice model (with a finite lattice constant) in $1952,{ }^{70}$ and later in a more general frame in $1973,{ }^{71}$ of the 
first trials for its theoretical derivation. As it is true that this expression is not the only mathematical representation of a physical phenomena that subsists almost a century and a quarter after his publication, it is also true and unusual that a law with a so "beautiful simplicity" (as Mathias himself referred to), ${ }^{72}$ has still validity according not only to its highly comparative accuracy regarding more modern methods for the estimation of critical densities, but also to the applications that have been conformed or added to those initially established. ${ }^{73}$

\section{SUPPLEMENTARY MATERIAL}

The Figure 1 showing the schematic diagram of the arrangement used for the measuring of saturated liquid and vapour densities of oxygen at the Leyden Physical Laboratory is available on http:// quimicanova.sbq.org.br, in PDF format, with free access.

\section{ACKNOWLEDGMENTS}

I am indebted with F. Darbois and S. Smith from Elsevier's Global Rights Department for permission to reproduce the photographs of Louis Paul Cailletet and Sydney Young, respectively, in my paper. I thank to the Président de Clermont Communauté and the Observatoire de Physique du Globe de Clermont-Ferrand for the photograph and biographical information of Émile Ovide Joseph Mathias. I am also grateful for the helpful comments did by the anonymous reviewers on a draft of this paper.

\section{REFERENCES}

1. Cagniard de la Tour, C.; Ann. Chim. Phys. 1822, 21, 127, 178; Ann. Chim. Phys. 1823, 22, 410.

2. Andrews, T.; Phil. Trans. 1869, 159, 575.

3. van der Waals, J. D.; Verhan. Konink. Akad. van Wetens. 1880, $20,1$.

4. Gouy, L. G.; C. R. Séances Acad. Sci. 1892, 115, 720.

5. Levelt-Sengers, J. M. H.; Physica 1979, 98A, 363.

6. Moureau, H.; C. R. Séances Acad. Sci. 1977, 285, 81; Wisniak, J.; Indian J. Chem. Technol. 2003, 10, 223.

7. Cailletet, L. P.; C. R. Séances Acad. Sci. 1869, 68, 395, 723; C. R. Séances Acad. Sci. 1875, 80, 487; Ann. Chim. Phys. 1875, 6, 429.

8. Cailletet, L. P. ; C. R. Séances Acad. Sci. 1872, 74, 1282.

9. Cailletet, L. P.; C. R. Séances Acad. Sci. 1870, 70, 1131; C. R. Séances Acad. Sci. 1872, 75, 77; C. R. Séances Acad. Sci. 1879, 88, 61; C. R. Séances Acad. Sci. 1880, 90, 210.

10. Cailletet, L. P.; C. R. Séances Acad. Sci. 1877, 85, 1213.

11. Cailletet, L. P.; C. R. Séances Acad. Sci. 1877, 85, 1270, 1016; C. R. Séances Acad. Sci. 1878, 86, 97; C. R. Séances Acad. Sci. 1880, 91, 522, 815; C. R. Séances Acad. Sci. 1882, 94, 1249; C. R. Séances Acad. Sci. 1885, 100, 1033; Cailletet, L. P.; Hautefeuille, P. G.; C. R. Séances Acad. Sci. 1881, 92, 840, 901 .

12. Cailletet, L. P.; C. R. Séances Acad. Sci. 1882, 94, 1224; C. R. Séances Acad. Sci. 1883, 97, 1115; C. R. Séances Acad. Sci. 1884, 98, 1565.

13. Cailletet, L. P.; C. R. Séances Acad. Sci. 1874, 78, 411; C. R. Séances Acad. Sci. 1876, 83, 1211; C. R. Séances Acad. Sci. 1877, 84, 82; C. R. Séances Acad. Sci. 1888, 106, 1055.

14. Maurain, Ch.; C. R. Séances Acad. Sci. 1942, 214, 585; Wisniak, J.; Educ. Quím., in press.

15. Cailletet, L. P.; Bouty, E. M. L.; C. R. Séances Acad. Sci. 1885, 100, 1188.

16. Faraday, M.; Ann. Chim. Phys. 1823, 24, 403.

17. Wroblewski, Z.; C. R. Séances Acad. Sci. 1886, 102, 1010.

18. Amat, L.; Bull. Soc. Chim. 1886, 45, 482.

19. Cailletet, L. P.; Mathias, E.; C. R. Séances Acad. Sci. 1886, 102, 1202; J. Phys. Théor. Appl. 1886, 5, 549 .
20. Cailletet, L. P.; C. R. Séances Acad. Sci. 1882, 94, 623.

21. Fairbairn, W.; Tate, T.; Phil. Trans. 1860, 150, 185; Ann. Chim. Phys. 1861, 62, 249; Herwig, H.; Ann. Phys. 1869, 137, 19; Wüllner, A.; Grotrian, O.; Ann. Phys. Chem. 1880, 11, 545.

22. Ansdell, G.; Proc. Roy. Soc. 1879-1880, 30, 117

23. Yaws, C.; Thermophysical properties of chemical and hydrocarbons, William Andrew: Norwich, 2008.

24. Cailletet, L. P.; Mathias, E.; C. R. Séances Acad. Sci. 1887, 104, 1563; J. Phys. Théor. Appl. 1887, 6, 414.

25. Young, S.; Proc. Roy. Soc. A 1915, 91, 1xv.

26. Amagat, E.-H.; C. R. Séances Acad. Sci. 1892, 114, 1093; J. Phys. Théor. Appl. 1892, 1, 288.

27. Cailletet, L. P.; Colardeau, E.; C. R. Séances Acad. Sci. 1891, 112, 563, 1170.

28. Atkins, W. R. G.; Obit. Not. Fell. Roy. Soc. 1938, 2, 370.

29. Young, S.; Proc. Phys. Soc. 1892, 11, 233; Phil. Mag. 1892, 33, 153.

30. Young, S.; J. Chem. Soc. Trans. 1891, 59, 37.

31. Young, S.; Proc. Phys. Soc. 1894, 12, 447; Phil. Mag. 1892, 37, 1.

32. Young, S.; Thomas, G. L.; Proc. Phys. Soc. 1892, 12, 134; Phil. Mag. 1892, 34, 507

33. Mathias, E.; Ann. Fac. Sci. Toulouse 1892, 6, M1; J. Phys. Théor. Appl. 1892, $1,53$.

34. Guye, P. A.; Arch. Sci. Phys. Nat. 1894, 31, 38, 176.

35. Meyer, O. E.; Kinetic theory of gases, Longman: Londres, 1899; Heilborn, E.; Ann. Chim. Phys. 1892, 27, 352.

36. Thorpe, T. E.; Rucker, M. A.; J. Chem. Soc. Trans. 1884, 45, 135.

37. Mendeleev, D. I.; J. Chem. Soc. Trans. 1884, 45, 126.

38. Young, S.; Proc. Phys. Soc. 1899-1901, 17, 480; Phil. Mag. 1900, 50, 291.

39. Mathias, E.; C. R. Séances Acad. Sci. 1899, 128, 1389; C. R. Séances Acad. Sci. 1904, 139, 359; J. Phys. Théor. Appl. 1899, 8, 407; J. Phys. Théor. Appl. 1905, 4, 77.

40. Mathias, E.; C. R. Séances Acad. Sci. 1909, 148, 1102.

41. Mathias, E. In Het Natuurkundig Laboratorium der Rijksuniversiteit te Leiden in de Jaren 1904-1922, Kamerlingh-Onnes, H.; Crommelin, C. A., eds.; Eduard Ijdo: Leiden, 1922, chap. 6.

42. Anonymous; C. R. Séances Acad. Sci. 1909, 149, 1292.

43. Anonymous; C. R. Séances Acad. Sci. 1920, 171, 1292.

44. Crosland, M.; Galvez, A.; Soc. Stud. Sci. 1989, 19, 71.

45. Mathias, E.; Kamerlingh Onnes, H.; Proc. Sec. Sci. Konink. Akad. Wetensch. Amsterdam (KNAW) 1910-1911, 13, 939; C. R. Séances Acad. Sci. 1910, 151, 213, 474.

46. Mathias, E.; Kamerlingh-Onnes, H.; Crommelin, C.-A.; Proc. Sec. Sci. Konink. Akad. Wetensch. Amsterdam (KNAW) 1912-1913, 15, 960; C. R. Séances Acad. Sci. 1913, 156, 129.

47. Crommelin, C.-A.; Onnes, H. K.; Mathias, E.; Proc. Sec. Sci. Konink. Akad. Wetens. Amsterdam (KNAW) 1914-1915, 17, 953; Mathias, E.; Kamerlingh-Onnes, H.; Crommelin, C.-A.; C. R. Séances Acad. Sci. 1915, 160, 237.

48. Crommelin, C.-A.; Kamerlingh-Onnes, H.; Mathias, E.; Proc. Sec. Sci. Konink. Akad. Wetens. Amsterdam (KNAW) 1921, 23, 1175; Mathias, E.; Crommelin, C.-A.; Kamerlingh-Onnes, H.; Commun. Phys. Lab. Univ. Leiden 1921, 154B, 15; Mathias, E.; Crommelin, C.-A.; KamerlinghOnnes, H.; C. R. Séances Acad. Sci. 1921, 172, 261.

49. Mathias, E.; Crommelin, C.-A.; Kamerlingh-Onnes, H.; C. R. Séances Acad. Sci. 1922, 175, 933.

50. Mathias, E.; Crommelin, C.-A.; Kamerlingh Onnes, H.; Swallow, J. C.; Proc. Sec. Sci. Konink. Akad. Wetens. Amsterdam (KNAW) 1925, 28, 526; C. R. Séances Acad. Sci. 1925, 180, 1005.

51. Mathias, E.; Crommelin, C.-A.; Garfit-Watts, H.; C. R. Séances Acad. Sci. 1927, 185, 1240.

52. Mathias, E.; Bijleveld, W. J.; Grigg, Ph. P.; C. R. Séances Acad. Sci. 1932, 194, 1708. 
53. Mathias, E.; Crommelin, C.-A.; Meihuizen, J.-J.; C. R. Séances Acad. Sci. 1937, 204, 630

54. Mathias, E.; Le point critique des corps purs, Naud: Paris, 1904.

55. Cardoso, E.; Arch. Sci. Phys. Nat. 1912, 34, 20, 127; Vespignani, G. B.; Gazz. Chim. Ital. 1903, 33, 73; Guye, Ph.; Mallet, E.; C. R. Séances Acad. Sci. 1902, 134, 168.

56. Cardoso, E.; C. R. Séances Acad. Sci. 1911, 153, 257.

57. van Laar, J. J.; Z. Anorg. Chem. 1925, 146, 263; Hertz, W.; Z. Anorg. Chem. 1925, 149, 230.

58. Lautié, R.; C. R. Séances Acad. Sci. 1935, $200,58$.

59. Mezger, E.; C. R. Séances Acad. Sci. 1947, 225, 108.

60. von Jüptner, H.; Z. Phys. Chem. 1913, 85, 1.

61. Benson, S. W.; J. Phys. Chem. 1948, 52, 1060.

62. Cornfeld, A. B.; Carr, H. Y.; Phys. Rev. Lett. 1972, 29, 28, 320; Zollweg, J. A.; Mulholland, G. W.; J. Chem. Phys. 1972, 57, 1021; Levelt Sengers, J. M. H.; Straub, J.; Vicentini-Missoni, M.; J. Chem. Phys. 1971, 54, 5034

63. Widom, B.; Rowlinson, J. S.; J. Chem. Phys. 1970, 52, 1670; Widom, B.; Stillinger, F. H.; J. Chem. Phys. 1973, 58, 616; Mermin, N. D.; Rehr, J. J.; Phys. Rev. Lett. 1971, 26, 1155; Mermin, N. D.; Phys. Rev. Lett. 1971, 26, 169; Hemmer, P. C.; Stell, G.; Phys. Rev. Lett. 1970, 24, 1284.
64. Jüngst, S.; Knuth, B.; Hensel, F.; Phys. Rev. Lett. 1985, 55, 2160; March, N. H.; United Nations educational, scientific and cultural organization and International Atomic Energy Agency document, Trieste, 2007.

65. Singh, R. R.; Pitzer, K. S.; J. Chem. Phys. 1990, 92, 3096.

66. Tobler, F. C.; Ind. Eng. Chem. Res. 1996, 35, 811

67. Huang, Y. H.; Chen, G. B.; Li, X. Y.; Arp, V.; Int. J. Thermophys. 2005, 26, 729; Nowak, P.; Kleinrahm, R.; Wagner, W.; J. Chem. Thermodyn. 1997, 29, 1157; J. Chem. Thermodyn. 1996, 28, 1441.

68. Ley-Koo, M.; Green, M. S.; Phys. Rev. A: At., Mol., Opt. Phys. 1981, $23,2650$.

69. Kulinskii, V. L.; Malomuzh, N. P.; Physica A 2009, 388, 621; Wang, J.; Anisimov, M. A.; Phys. Rev. E: Stat., Nonlinear, Soft Matter Phys. 2007, 75, 051107; Anisimov, M. A.; Wang, J.; Phys. Rev. Lett. 2006, 97, 025703; Wang, J.; Cerdeiriña, C. A.; Anisimov, M. A.; Sengers, J. V.; Phys. Rev. E: Stat., Nonlinear, Soft Matter Phys. 2008, 77, 031127.

70. Lee, T. D.; Yang, C. N.; Phys. Rev. 1952, 87, 410.

71. Biswas, A. C.; Pramana 1973, 1, 109; J. Stat. Phys. 1973, 7, 131.

72. Mathias, E.; C. R. Séances Acad. Sci. 1937, 204, 1097.

73. Davies, H.; Philos. Mag. 1912, 24, 415. 


\section{THE HISTORY OF THE RECTILINEAR DIAMETER LAW}

\section{Simón Reif-Acherman}

Escuela de Ingeniería Química, Universidad del Valle, A. A. 25360 Unicentro, Cali, Colombia

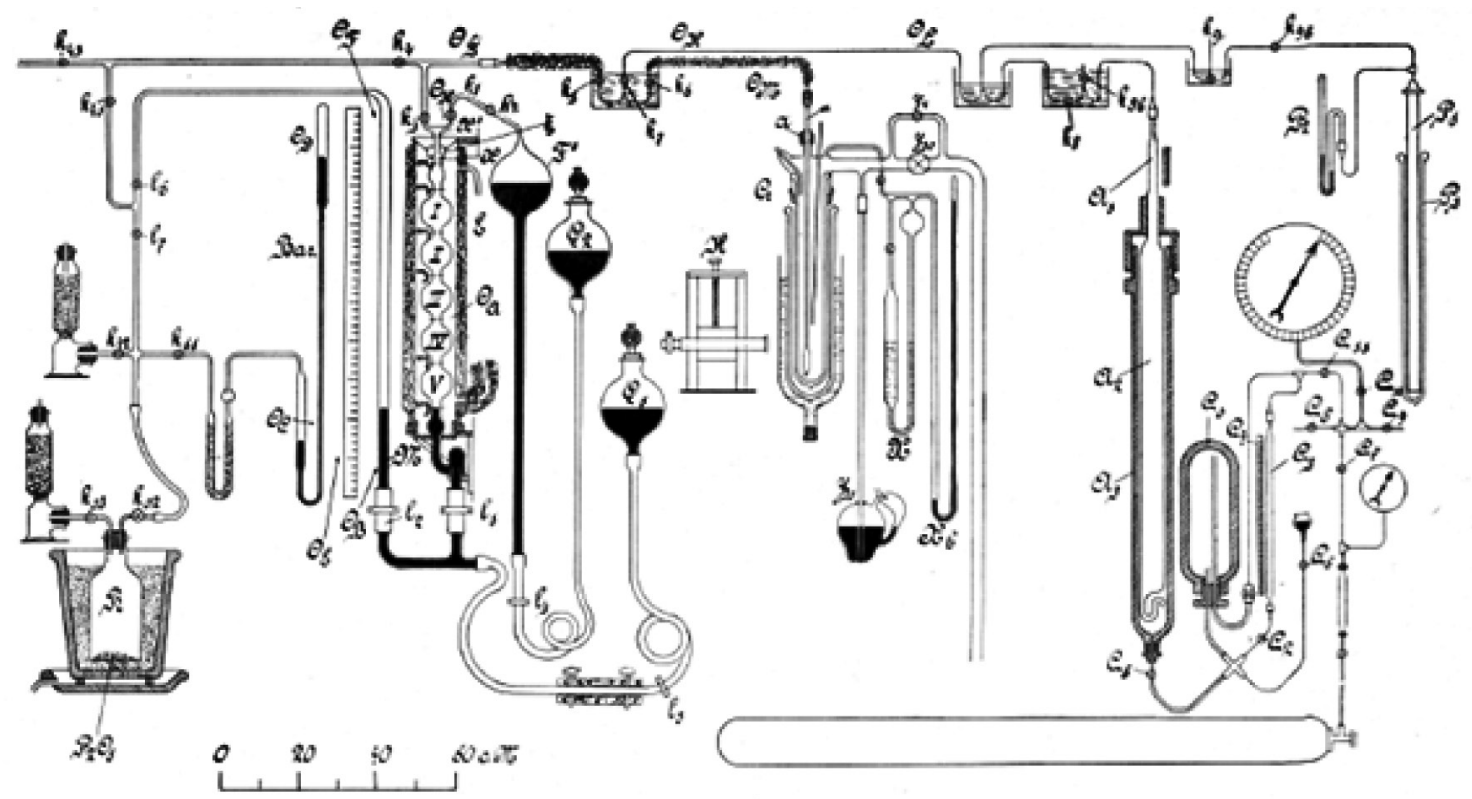

Figure 1S. Schematic diagram of the arrangement used in Leiden for the measuring of saturated liquid and vapour densities of oxygen (from ref. 45) 